\title{
Publishing at Any Cost? The Need for the Improvement of the Quality of Scholarly Publications
}

\author{
Maria José Sá ${ }^{1}$, Carlos Miguel Ferreira ${ }^{2}$, Ana Isabel Santos ${ }^{3} \&$ Sandro Serpa $^{4}$ \\ ${ }^{1}$ CIPES - Centre for Research in Higher Education Policies, Matosinhos, Portugal \\ ${ }^{2}$ Interdisciplinary Centre of Social Sciences - CICS.NOVA; ISCTE - University Institute of Lisbon, Portugal \\ ${ }^{3}$ University of the Azores, Faculty of Social Sciences and Humanities; Interdisciplinary Centre for Childhood and \\ Adolescence -NICA -Uac, Ponta Delgada, the Azores, Portugal \\ ${ }^{4}$ University of the Azores, Faculty of Social and Human Sciences, Department of Sociology; Interdisciplinary Centre \\ of Social Sciences - CICS.UAc/CICS.NOVA.UAc; Interdisciplinary Centre for Childhood and Adolescence - NICA - \\ UAc, Ponta Delgada, the Azores, Portugal \\ Correspondence: Sandro Serpa, University of the Azores, Faculty of Social and Human Sciences, Department of \\ Sociology. Rua da Mãe de Deus, 9500-321 Ponta Delgada, the Azores, Portugal.
}

Received: March 8, 2020

doi:10.5430/ijhe.v9n3p214
Accepted: March 26, 2020

Online Published: March 27, 2020

\begin{abstract}
At a time of great dynamism among publishers of scientific publications, with the inevitability of Open Access and the ease of publishing online at low cost, it is possible to find publications with different levels of scientific respectability. In this context, the improvement of the quality of scholarly publications emerges as a critical element for publishers, authors and academic institutions, as well as for society in general. This opinion piece discusses Open Access journals with different levels of quality, focusing on the following quality-promoting measures: blacklists, author's preparation, and institutional prevention. The analysis allows concluding that the open review will be one of the key elements in the process of clarification and promotion of the level of quality and consequent scientific respectability of each of the Journals, of the thousands currently existing, a number that is likely to increase.
\end{abstract}

Keywords: academic publications, scholarly publications, quality assessment, legitimate journals, open review

\section{Introduction}

Over the last 20 years, scholarly publications have experienced several and profound changes. From the many changes that took place, Cress and Sarwer (2019) highlight, as the most relevant, the following ones: "1. Digital publishing/technology advancements (including online peer-review submission websites); 2. Open access (OA); 3. Social media; 4. Bibliometric analysis, altmetrics, and journal analysis beyond Impact Factor; 5. Artificial intelligence" (p. 2). The printed publication becomes less relevant in comparison with the digital publication, for example, through a journal website. Likewise, bibliographic search in digital media (through specialised search engines and databases) is potentially much more efficient than classical search, not to mention the ease of communication through electronic mail (Liyanapathirana, 2019).

Specifically in academic publications (ejournals and ebooks), the unstoppable movement, in our opinion, of Open Access - which makes the manuscripts available for reading by any user with internet access without the need for any payment or subscription - transformed radically the scholarly publication, by giving it a new dynamic of direct competition with the journals that provide the traditional printed information (Garland, 2019).

In this context of ease of publication, digital communication and collaboration, even among academics themselves, there is increasing pressure for academics to publish. The publication of scientific articles has direct consequences in professional terms, notably promotion, tenure and attribution of research grants, just to name a few (To \& Yu, 2020). The authors provide astonishing numbers of academics and researchers, and academic publications in the higher education arena alone, to illustrate this phenomenon that is growing in complexity: (i) the number of academics at the global level raised from 4 million in 1980 to 13.1 million in 2018; (ii) the number of academic publications raised from 0.65 million in 1980 to 3.16 million in 2018; and (iii) it is expected that, in 2020, the number of researchers reaches 13.6 million, with 3.21 million academic articles published (To \& Yu, 2020). 
The circumstances described above created the conditions for the emergence of important problems related to the quantity and, mainly, the quality of this type of publications (Kimotho, 2019; To \& Yu, 2020). Among these concerns, To and $\mathrm{Yu}$ (2020) highlight the increasing demand, in an open-access environment, for scientific papers and data, which, in turn, causes a greater demand for works published in a short time, with the risk of a lower quality peer review, which will reflect, unavoidably, also on the low quality of published papers. This intensification in demand increases the number of predatory journals, which frequently causes academic flaws, notably fabrication, falsification, plagiarism and duplicate publication, among other issues, which are cause for serious concern. In this line, Lekamwasam and Waidyarathne (2018) sustain that online open-access has caused the emergence of a myriad of fake or predatory journals and that this proliferation is a threat to trustworthy journals and publishers. The authors further contend that this publication industry flourishes based on the "publish or perish" current academic culture Lekamwasam \& Waidyarathne, 2018, p. 1).

This status quo has driven the production of studies on several topics related to it. Following Björk et al. (2019), some examples are, from among the many that exist, are the features of predatory open-access publishers and journals; the role of blacklists and whitelists; the geographical distribution of predatory journals and authors; the abstract and indexing of Predatory journals in important databases, notably Web of Science and Scopus; the motivation of authors to publish in predatory journals; and the reviews with flawed and senseless manuscripts.

In summary, at a time when there is a great dynamism among the publishers of scientific publications, with open-access emerging as an inevitability, and the ease of publishing online, there are publications with different levels of scientific legitimacy. The improvement of the quality of scholarly publications, in this context, is a key element both for publishers, authors and academic institutions. This opinion piece discusses several types of open-access journals with below-average quality, focusing on the following preventive measures: the existence of blacklists, author's preparation, and institutional prevention.

\section{Quality of Scholarly Publications}

\subsection{Different Quality Journals}

A variety of journals publish articles with distinct scientific quality. At one of the extreme types of poor-quality publications are the ones released in the so-called predatory journals, whose number has increased enormously in recent years (Ross-White et al., 2019). Despite the difficulty in defining them (Cobey et al., 2019), they can be characterised, in general, as journals whose first and last goal is profit, frequently through the payment of a publication fee or charge that is characteristic of most Journals that operate in open-access, albeit not exclusively (Teixeira da Silva \& Tsigaris, 2018). To attain this purpose, the manuscripts are not subject to serious peer review and, consequently, the quality of what is published is not a purpose of these journals (Ross-White et al., 2019; Watson, 2019; Teixeira da Silva \& Tsigaris, 2018; Cress \& Sarwer, 2019).

Although there is not a unique definition of predatory journals or publishers (e.g., Beall, 2012; Avelar-Rodriguez, 2019), which makes it difficult to apprehend and fight them, Cukier et al. (2019) sustain that this sort of journals "[...] have self-interest as a goal, and are often motivated to accept as many articles as possible to profit from article processing charges (APCs) which are common at OA journals" (p. 5). As a consequence, these publishers and the journals they are responsible for sacrifice quality control of articles beforehand, upon their publication and in the post-publication stage (with the possibility of retraction, for example), concurrently with their rapid acceptance and publication (Shrestha et al, 2019; Liyanapathirana, 2019; Dobusch \& Heimstädt, 2019) with excessive email spam (Wood \& Krasowski, 2020; Avelar-Rodriguez, 2019; Grudniewicz et al., 2019). Avelar-Rodriguez (2019) is a heavy critic of this positioning and warns that the only goal of predatory journals is to profit financially from the publication of research that has frequently low quality, but since the authors pay for the publication fee, their papers are published, regardless of their scientific soundness. Laine and Winker (2017) offer a set of features that help identify a predatory journal (Table 1). 
Table 1. "Warning Sign" features that help identify a predatory journal

Features

No information about publication fees in the Instructions for Authors.

No mention of peer review in the Instructions for Authors.

Little or no information about the editor or editorial board.

No location for the journal offices or it is very different from where the editors and editorial board are based.

The journal website is not easily accessible in an internet search.

The journal publishes a highly variable number of articles each year.

The journal sends standard e-mail requests for submissions, without specifying particular research areas.

Promised usual turnaround for review and publication is very rapid, making it unlikely to encompass the time necessary for a sound peer-review process.

Lengthy average reply time to messages from the editor or journal office.

The journal's name is very similar to the name of a well-known and reputed journal.

The publication fees are nonconforming with the scholarly publishing industry (either much higher or much lower than well-established journals).

It is difficult to identify articles published in the journal when searching Google Scholar or other databases.

Information about author affiliations and/or contact information is not present in published articles.

A person you know listed on the editorial board or journal staff is not aware of their affiliation with the journal.

Source: Adapted from Laine and Winker, 2017, p. 289.

In line with Avelar-Rodriguez (2019), Watson (2019) characterises this kind of journals as "pollution" and compares them to viruses, with the ability to mutate to avoid the risk of being detected. The author further argues that these journals have a single purpose: to get profit from the researchers' work.

Besides the predatory journals, other types of journals have emerged in this turbulent world of scientific publication. These are called clone journals and are characterised by being hijacked journals. They function as a forged mirror of a real and reliable journal, using its title and ISSN (International Standard Serial Number). As these journals "stole" the image from the authentic journal they cloned, they often get high impact factor from important indexing databases, e.g. Clarivate Analytics and Scopus (Asim \& Sorooshian, 2020). Table 2 depicts the main features of clone journals.

Table 2. Clone Journals

Features

(1) False claims to be members of the Committee on Publication Ethics (COPE) and the Open Access Scholarly Publishing Association (OASPA);

(2) False declarations of indexation in databases such as SCOPUS and Web of Science (WOS);

(3) Manuscript publication charges that are not visible;

(4) Non-transparency of the peer-review process, with unrealistically short peer review-to-publication turnaround times (e.g. one week);

(5) Non-existent publisher contact details: fake publishers do not have authentic postal addresses or any active telephone number; and

(6) Counterfeit publishers have small numbers of articles per year but have enormous editorial boards, or vice versa.

Source: Asim and Sorooshian, 2020, p. 2.

Some authors argue that many editors, and even reputed ones, ultimately use a profit demand component, which seems to be excessive. Two of these authors are Teixeira da Silva and Tsigaris (2018), who alert that (i) not all open-access journals are predatory; (ii) not all journals that charge fees are predatory; and (iii) many accountable 
journals and publishers already provide open-access content. Gades and Toth (2019) maintain that a good deal of renowned journals also have submission or processing fees, and the published articles are available in open-access.

Amaral (2018) offers an interesting and illustrative example of the charge (very high, from his standpoint) of the publication fee of a highly prestigious journal, which is indexed in the most acknowledged and legitimate databases. The author claims that the publisher does little to justify such a fee. All he/she has to do was (i) providing a simple online platform for submission; (ii) searching for reviewers in a process that is unknown to those who submit manuscripts; (iii) taking over three months to provide the author(s) writing short feedback, which he/she got from the reviewers who probably offer their expertise free of charge; (iv) taking one or two more months to inform the author(s) that the manuscript is accepted. On top of it, proofreading may be a nightmare, especially if the article has figures or tables. On the opposite side of this equation, the author(s) work for two or more years putting together a manuscript, from the literature review, data collection and analysis (if it is an empirical study) to the discussion of the results. In the author's words, this does not "sound like a fair deal" (Amaral, 2018, p. 1645).

However, there are journals that, although not having - at least at one given time - high academic recognition, are genuine (Avelar-Rodriguez, 2019). Terms such as predatory journal, among others, may be wrongfully used to characterise these journals and fail to reflect the different levels of quality of the high number of scholarly journals. Dobusch, \& Heimstädt (2019) offer a set of types of open-access journals that have below-average quality, detailed in Table 3.

Table 3. Types of Open Access journals with below-average quality

\begin{tabular}{lll}
\hline \multicolumn{1}{c}{ Journal type } & \multicolumn{1}{c}{ Characteristics } & \multicolumn{1}{c}{ Orientation } \\
\hline Aspirant Journal & Sometimes APCs, below-average peer review & Primarily science-driven \\
Junk Journal & APCs, formal but superficial peer review & Primarily profit-driven \\
Fake Journal & APCs, no peer review & Purely profit-driven \\
\hline
\end{tabular}

Source: Dobusch, \& Heimstädt, 2019, p. 610.

Dobusch, \& Heimstädt (2019) describe these three types of open-access journals as follows: (i) Aspirant journals have low quality in terms of publications and peer-reviewers. Although they charge publication fees, profit is not their main goal and, hence, they are not predatory journals. (ii) Junk journals -profit is their main goal. Thus, they charge publication fees, the level of demand is low, and articles are accepted with minor changes. (iii) Fake journals - charge publication fees but the manuscripts do not undergo a peer-review process.

\subsection{Improvement in the Quality of Scholarly Publications}

\subsubsection{Blacklists}

Beall's (2017a) definition of lists of (possibly or probably) predatory publications (that included both publishers and journals and that he named "blacklists") made those lists highly visible and influential. These lists were, at the time they were released, a relevant source of academic consultation, especially for new scholars who were novice in publishing and searched for a reputable journal to publish their research. For example, in the specific case of the lists offered by Jeffrey Beall, they were accessible online for the general public, but they were removed in 2017. When Beall explained why he withdrew the lists, he stated: "facing intense pressure from my employer, the University of Colorado Denver, and fearing for my job, I shut down the blog and removed all its content from the blog platform" (Beall, 2017b, p. 273), but researchers keep updating these lists. Currently, researchers use the Cabell's Blacklist, as it is freely accessible on the internet and whose main purpose is to make the "community aware of the growing threats and to keep academia protected from exploitative operations" (Cabells, 2020, online). However, some experts deem the criteria for defining these lists debatable. For instance, Teixeira da Silva and Tsigaris (2018) claim that Beall's (2017a) definition of blacklists "was influenced by excessive personal opinion (i.e., subjectivity), and mired in scandal and controversy" (p. 782). Blacklists started by presenting lists of publishers and isolated journals, possibly with predatory features. Currently, there are several other blacklists (Cf. Teixeira da Silva \& Tsigaris, 2018). However, they have several limitations, which may make them academically invalid (Teixeira da Silva \& Tsigaris, 2018). The authors put forth the main limitations of blacklists, depicted in Table 4. 
Table 4. Caveats of the blacklists

1) They are prone to having false positives.

2) Inclusion criteria are opaque resulting in not only a high number of false positives but a very high false discovery rate

3) Blacklists may violate article 11 of the declaration of human rights to be presumed innocent until found guilty in a public trial by the law.

4) Those that create blacklists can face legal and personal challenges.

5) Blacklists suffer from personal biases (e.g., Beall's own anti-OA [Open Access] views).

6) Blacklists can cause irreversible reputational damage to authors, editors and publishers.

7) Blacklists can cause serious friction between colleagues, between librarians and scientists, and between scientists and other scientists as a result of their erroneous use and applications.

8) Blacklists can be used as a poor excuse by academic assessors and decision makers to save them valuable time by not having to read manuscripts to assess their individual quality (i.e., laziness).

Source: Teixeira da Silva and Tsigaris, 2018.

The dynamics that shape the production and review of a list that could be carried out by collective academic councils, who would be responsible for rating a journal or publisher's academic weaknesses (Kimotho, 2019), besides being potentially unclear, may deeply affect academics, even though they have a stance of good faith, taking into account the dynamics that shape the reformulation of this type of lists (Teixeira da Silva \& Tsigaris, 2018).

\subsubsection{Preparation of the Authors}

In the above-described context, the preparation of authors, especially those who are in the early stages of their career as researchers, is critical. Senior faculty members play a key role in advising their younger and unexperienced colleagues on the publishing process (Burggren et al., 2018; Liyanapathirana, 2019; Watson, 2019). Furthermore, contrary to what could be expected, it may happen that many university students, even at the graduate level, are not very familiar or particularly concerned with these quality issues of scientific publication (Liyanapathirana, 2019; Santos \& Serpa, 2017). Cress and Sarwer (2019) argue that education is critical in preventing predatory journals to thrive at the expense of researchers that need to publish, and the traditional publishers have to reaffirm, based on their reputation and knowledge, their hegemony in the scholarly publishing field.

However, the relatively small number of western-published journals fails to succeed in meeting the need to publish on the part of a very high number of researchers. This is due, not always to the poor quality of manuscripts, but rather to the relevance of issues submitted for publication. This fact has to be considered, as it takes on substantial relevance and is one of the reasons for predatory journals to thrive (Kimotho, 2019; Björk, 2019).

\subsubsection{Institutional Prevention}

The number of international publications is a key element in the evaluation of scholarship in academic promotion, tenure and research (Schimanski \& Alperin, 2018). Taking the example of Brazil, and according to Pires et al. (2020), the Qualis journal ranking system has been used as an indicator of the quality of the research carried out, and it is an important tool in assessing the publishing practices in this country between 2007 and 2016. Given that the assessment of scientific production in the country defines the allocation of financial resources, these assessment criteria are widely used by researchers in the search for better scores and, hence, higher funding.

Burggren et al. (2018) advocate that, instead of using complex metrics, evaluation committees, whether for merit, promotion or tenure, should base their assessments on the quality of the work published, as well as the quality of the journal itself. This would lead to a redefinition in terms of the choice of the journals to publish in on the part of academics (Shaghaei et al., 2018; Teixeira da Silva \& Tsigaris, 2018; Cress \& Sarwer, 2019; Severin \& Low, 2019).

\section{The Need for Open Review}

In the current context of scholarly publication, Garland (2019) maintain that there is the "Tall Poppy Syndrome" (TPS) (p. 29), which is a metaphor for the existing competition between well-established journals and e-journals and that may "lead to one journal cutting the other down by acceptable behavior [sic] such as disruption (justification). The predatory journals want to cut down both prestigious and e-journals but by unacceptable behavior [sic] 
(egregious) such as an inappropriate business model” (p. 29).

In the process of promoting control and increasing the scientific quality of publications, the peer-review procedure will continue, it seems to us, to be critical. The lack of a sound peer-review process - that characterises predatory journals - enables a quicker publication on the part of academics, who thus advance in their careers faster than if they published in higher-quality journals, which have a more thorough and, hence, longer evaluation process. The peer-review process is one of the most important gatekeepers of the quality of academic publications, and it is endangered by this "overcrowded system" (Cress \& Sarwer, 2019, p. 2).

A more transparent and inclusive peer-review process, being open to public scrutiny, may add to the solution by separating quality journals from others, thus legitimising the former (Dobusch \& Heimstädt, 2019; Teixeira da Silva \& Tsigaris, 2018; To \& Yu, 2020; Serpa \& Ferreira, 2019). Table 5 provides an overview of open peer-review practices and their description.

Table 5. Open peer review practices

\begin{tabular}{l|l}
\hline Practice & Description \\
\hline $\begin{array}{l}\text { Transparent peer review } \\
\text { Open identities }\end{array}$ & Authors and reviewers know each other's identities. \\
\hline $\begin{array}{l}\text { Open reports } \\
\text { Reports are published together with the accepted manuscript. }\end{array}$ \\
\hline Open platforms & Review is not organized by the issuing journal, but by another organization. \\
\hline $\begin{array}{l}\text { Dialogical peer review } \\
\text { Open participation }\end{array}$ & All members of the wider community can review an unpublished manuscript. \\
\hline Open interactions & $\begin{array}{l}\text { Direct reciprocal discussion between authors and reviewers is possible and is } \\
\text { promoted. }\end{array}$ \\
\hline Open pre-review manuscripts & $\begin{array}{l}\text { Original manuscripts are made available on preprint servers before the review } \\
\text { process begins. }\end{array}$ \\
\hline Open final-version commenting & Open commenting on the final manuscript is possible. \\
\hline
\end{tabular}

Source: Adapted from Ross-Hellauer (2017), in Dobusch and Heimstädt, 2019, p. 613.

In a very clear way, Dobusch and Heimstädt (2019) sustain that a sound and straightforward peer-review process is one of the most important ways that high-profile journals have to distinguish from predatory journals. The authors further propose that "journals can experiment with open identities, open reports, and some types of open platforms. [...] When practising open identities in peer review, authors and reviewers know each other's identities. Once an article is published, it would not only indicate the name of its authors but also of the reviewers that had commented on the manuscripts" (p. 613).

\section{Final Remarks}

Predatory journals undermine the integrity and credibility of science (Teixeira da Silva \& Tsigaris, 2018). However, it is important to use some caution when condemning predatory journals, especially within some scientific fields. On their 2018 study, Shaghaei et al. (2018) alert that common views about predatory journals may not always be accurate, and there is a grey zone between real and presumed predatory journals.

As Ross-White et al. (2019) rightfully maintain, both bibliographic databases and journals are in constant change and, hence, it not possible to generalise current results. Yet, that authors alert that "predatory publications are not likely to disappear any time soon. Systematic reviewers must be cautious both in evaluating research by carefully considering its source and in seeking publication themselves" (Ross-White et al., 2019, p. 60).

It is concluded that the open review is one of the core elements in the process of clarification and promotion of the level of quality and consequent scientific respectability of each of the journals, of the thousands currently operating, which is a number that is likely to increase.

\section{Acknowledgements}

The authors would also to thank the reviewers and the editor for their comments and suggestions. 


\section{Funding}

University of Azores,

Interdisciplinary

Centre

of

Social

Sciences-CICS.UAc/CICS.NOVA.UAc,UID/SOC/04647/2019, with the financial support of FCT/MEC through national funds and when applicable co-financed by FEDER under the PT2020 Partnership Agreement.

\section{References}

Amaral, O. B. (2018). All publishers are predatory - Some are bigger than others. Anais da Academia Brasileira de Ciências, 90(2), 1643-1647. https://doi.org/10.1590/0001-3765201820170959.

Asim, Z., \& Sorooshian, S. (2020). Clone journals: A threat to medical research. Sao Paulo Medical Journal. https://doi.org/10.1590/1516-3180.2018.0370160919

Avelar-Rodriguez, D. (2019). Predatory journals: What you need to know about them? International Journal of Medical Students, 7(3), 92-94. https://doi.org/10.5195/ijms.2019.449

Beall J. (2012). Criteria for determining predatory open-access publishers (2nd ed.). Retrieved from https://scholarlyoa.files.wordpress.com/2012/11/criteria-2012-2.pdf

Beall, J. (2017a). Writer's Forum-Predatory journals, peer review, and education research. New Horizons in Adult Education \& Human Resource Development, 29(1), 54-58. https://doi.org/10.1002/nha3.20173

Beall, J. (2017b). What I learned from predatory publishers. Biochemia Medica, 27(2), 273-278. https://doi.org/10.11613/BM.2017.029.

Björk, B.-C., Kanto-Karvonen, S., \& Harviainen, T. (2019). How frequently are articles in predatory open access journals cited. Preprint. Retrieved from https://arxiv.org/ftp/arxiv/papers/1912/1912.10228.pdf

Burggren, W., Madasu, D., Hawkins, K.S., \& Halbert, M. (2018). Marketing via e-mail solicitation by predatory (and legitimate) journals: An evaluation of quality, frequency, and relevance. Journal of Librarianship and Scholarly Communication, 6(General Issue), eP2246. https://doi.org/10.7710/2162-3309.2246

Cabells Scholarly Analytics (2020, online). The journal blacklist. Retrieved from https://www2.cabells.com/about-predatory.

Cobey, K. D., Grudniewicz, A., Lalu, M. M., Rice, D. B., Raffoul, H., \& Moher, D. (2019). Knowledge and motivations of researchers publishing in presumed predatory journals: A survey. BMJ Open, 9(3), e026516. http://dx.doi.org/10.1136/bmjopen-2018-026516

Cress, P. E., \& Sarwer, D. B. (2019). Predatory journals: An ethical crisis in publishing. Aesthetic Surgery Journal Open Forum, 1(1), 1-3. https://doi.org/10.1093/asjof/ojz001

Cukier, S., Lalu, M. M., Bryson, G. L., Cobey, K. D., Grudniewicz, A., \& Moher, D. (2019). Defining predatory journals and responding to the threat they pose: A modified Delphi consensus process. BMG Open, 10, e035561. https://doi.org/10.1101/19010850

Dobusch, L., \& Heimstädt, M. (2019). Predatory publishing in management research: A call for open peer review. Management Learning, 50(5), 607-619. https://doi.org/10.1177/1350507619878820

Gades, N. M., \& Toth, L. A. (2019). How to avoid becoming easy prey for "predatory" journals and why it matters. Comparative Medicine, 69(3), 164-166.

Garland, D. E. (2019). Prestigious journals, predatory publishers and the Tall Poppy Syndrome in medicine. Journal of Vaccines and Immunology, 5(1), 028-030. https://doi.org/10.17352/jvi

Grudniewicz, A., Moher, D., Cobey, K. D., Bryson, G. L., Cukier, S., Allen, K., ... Lalu, M. M. (2019). Predatory journals: No definition, no defence. Nature, 576, 210-212. https://doi.org/10.1038/d41586-019-03759-y

Kimotho, S. G. (2019). The storm around Beall's List: A review of issues raised by Beall's critics over his criteria of identifying predatory journals and publishers. African Research Review, 13(2), 1. https://doi.org/10.4314/afrrev.v13i2.1

Laine, C., \& Winker, M. A. (2017). Identifying predatory or pseudo-journals. Biochemia Medica, 27(2), 285-291. https://doi.org/10.11613/BM.2017.031

Lekamwasam, S., \& Waidyarathne, E. (2018). Predatory or fake journals: A real threat to the credible publishers. Galle Medical Journal, 23(2). https://doi.org/10.4038/gmj.v23i2.7974

Liyanapathirana, V. (2019). Predatory journals and conferences - A brief overview. Sri Lanka Journal of Medicine, 
28(1), 1. https://doi.org/10.4038/sljm.v28i1.118

Pires, A. D. S., Reategui, E. B., França, A. C. X., Bettinger, E., \& Franco, S. R. K. (2020). Implicações do sistema de classificação de periódicos Qualis em práticas de publicação no Brasil entre 2007 e 2016 [The implications of the Qualis journal classification in publication practices in Brazil between 2007 and 2016]. Education Policy Analysis Archives, 28, 25. https://doi.org/10.14507/epaa.28.4353

Ross-White, A., Godfrey, C. M., Sears, K. A., \& Wilson, R. (2019). Predatory publications in evidence syntheses. Journal of the Medical Library Association, 107(1). https://doi.org/10.5195/jmla.2019.491

Santos, A. I., \& Serpa, S. (2017). The importance of promoting digital literacy in higher education. International Journal of Social Science Studies, 5(6), 90-93. https://doi.org/10.11114/ijsss.v5i6.2330

Schimanski, L. A., \& Alperin, J. P. (2018). The evaluation of scholarship in academic promotion and tenure processes: Past, present, and future. F1000Research, 7, 1605. https://doi.org/10.12688/f1000research.16493.1

Serpa, S., \& Ferreira, C. M. (2019). Publicizing the peer reviewer: Legitimacy and quality of scientific publication. Science Open. https://doi.org/10.14293/S2199-1006.1.SOR-.PPWBIKL.v1

Severin, A., \& Low, N. (2019). Readers beware! Predatory journals are infiltrating citation databases. International Journal of Public Health, 64(8), 1123-1124. https://doi.org/10.1007/s00038-019-01284-3

Shaghaei, N., Wien, C., Holck, J. P., Thiesen, A. L., Ellegaard, O., Vlachos, E., \& Drachen, T. M. (2018). Being a deliberate prey of a predator - Researchers' thoughts after having published in a predatory journal. Liber Quarterly, 28. http://doi.org/10.18352/lq.10259

Shrestha, J., Subedi, S., Shokati, B., \& Chaudhary, A. (2019). Predatory journals: A threat to scholarly publishing. Journal of Education and Research, 8(1), 89-101. https://doi.org/10.3126/jer.v8i1.25482

Teixeira da Silva, J. A., \& Tsigaris, P. (2018). What value do journal whitelists and blacklists have in academia? The Journal of Academic Librarianship, 44(6), 781-792. https://doi.org/10.1016/j.acalib.2018.09.017

To, W. M., \& Yu, B. T. W. (2020). Rise in higher education researchers and academic publications. Emerald Open Research, 2, 3. https://doi.org/10.35241/emeraldopenres.13437.1

Watson, R. (2019). Predatory journals and the pollution of academic publishing. Journal of Nursing Management, 27(2), 223-224. https://doi.org/10.1111/jonm.12739

Wood, K. E., \& Krasowski, M. D. (2020). Academic e-mail overload and the burden of "academic spam". Academic Pathology, 7, 237428951989885. https://doi.org/10.1177/2374289519898858 